\title{
How Education Drives Demography and Knowledge Informs Projections
}

Wolfgang Lutz, lutz@iiasa.ac.at

Vegard Skirbekk, skirbekk@iiasa.ac.at

\section{Approved by}

Pavel Kabat

Director/CEO

October 17, 2013

Interim Reports on work of the International Institute for Applied Systems Analysis receive only limited review. Views or opinions expressed herein do not necessarily represent those of the Institute, its National Member Organizations, or other organizations supporting the work. 


\section{Contents}

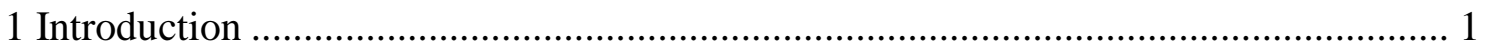

2 Adding Education as a Demographic Dimension in Global Population Projections .... 1

2.1 Functional Causality in the Context of Intervention Sciences................................. 4

2.2 Effects of Education on Health and Mortality ........................................................ 8

2.3 Effects of Education on Fertility...................................................................... 11

3 How are the Assumptions for Population Projections Defined? .................................... 14

3.1 The Meta-Science of Expert Knowledge........................................................... 16

3.2 The Systematic Inquiry of Expert Arguments Chosen for this Study ................... 17

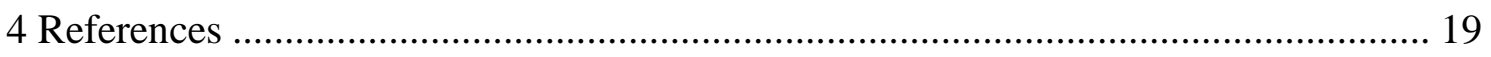




\section{Abstract}

This paper makes the case for systematically adding education to age and sex as a third standard demographic dimension. It directly addresses the question whether the pervasive association of education with demographic outcomes reflects a causal relationship. Based on the notion of functional causality, the paper reviews theoretical and empirical approaches for assessing this question according to three criteria. It also explores possible alternative explanations such as reverse causality and self-selection, concluding that a functional causal relationship between education and health- and fertility-related outcomes is supported by the evidence. The paper then describes the book's expert argument-based approach for defining assumptions for population projections and compares this approach with how European national statistical offices now make and use their assumptions for population projections. Against this background the approach chosen for this study combines a structured substantive inquiry among hundreds of international experts with formal statistical models. 


\section{Acknowledgments}

Funding for this work was made possible by the European Research Council (ERC) Advanced Investigator Grant focusing on “Forecasting Societies' Adaptive Capacities to Climate Change” (ERC-2008-AdG 230195-FutureSoc).

We acknowledge support by a Starting Grant of the European Research Council (ERC), Grant Agreement 241003-COHORT. 


\section{About the Authors}

Wolfgang Lutz is the Founding Director of the Wittgenstein Centre for Demography and Global Human Capital (IIASA, VID/ÖAW, WU); Leader of the World Population Program at IIASA; Director of the Vienna Institute of Demography of the Austrian Academy of Sciences; and full Professor of Applied Statistics (part time) at the Vienna University of Economics and Business.

Vegard Skirbekk is the Leader of the Age and Cohort Change Project (ACC) at the Wittgenstein Centre for Demography and Global Human Capital (IIASA, VID/ÖAW, WU), International Institute for Applied Systems Analysis. 


\title{
How Education Drives Demography and Knowledge Informs Projections
}

\author{
Wolfgang Lutz \\ Vegard Skirbekk ${ }^{1}$
}

\section{Introduction}

This paper provides the background necessary for understanding our approach to projecting population and human capital. First, we investigate the proper place of education in demographic analysis and the evidence for an underlying causal relationship between education and demographic outcomes. Second, we emphasize the importance of explicit assumptions undergirding population projections and detail our procedures for incorporating the views of hundreds of experts into sets of assumptions that drive the projections.

\section{Adding Education as a Demographic Dimension in Global Population Projections}

A major innovative feature of this volume is the systematic addition of educational attainment as a standard demographic dimension in addition to age and sex for demographic analyses, particularly for projections. The underlying assumption is that educational attainment is not just one of many socio-economic factors that matter for population, as it is often viewed in conventional demographic analysis, but is the single most important source of empirically observable population heterogeneity next to age and sex.

The suggestion of routinely adding educational attainment as a dimension of demographic analysis is not new. It was first proposed in a Population and Development Review article by Lutz, Goujon and Doblhammer-Reiter (1998), entitled "Adding education to age and sex". More recently, the idea of adding the education factor to demographic analysis was discussed by Lutz (2010) in a commentary entitled, "Education will be at the heart of $21^{\text {st }}$ century demography". It has also been the focus of two recent articles by Lutz and KC in Philosophical Transactions entitled, “Dimensions of Global Population Projections" (2010), and a review article in Science entitled, "Global Human Capital: Integrating Education and Population” (2011). In this last paper they argue that an additional demographic dimension should be added routinely to age and sex in population analyses and projections according to three criteria: (1) Its explicit consideration should be feasible in terms of available data and

\footnotetext{
${ }^{1}$ Sections 2.0, and 3 have been written by Wolfgang Lutz, Section 2.1 was mainly written by Wolfgang Lutz with inputs from Vegard Skirbekk, Sections 2.2 and 2.3 have been mainly written by Vegard Skirbekk with inputs from Wolfgang Lutz.
} 
methodology; (2) it should matter substantially in terms of altering population dynamics; and (3) it should be of interest in its own right in terms of its social and economic implications. Lutz and KC $(2011 ; 2010)$ address these criteria systematically, reaching the conclusion that educational attainment is the only additional demographic dimension that meets all three of these criteria and should hence be routinely and systematically included as a standard demographic dimension. On a more substantive level, this systematic addition of educational attainment can be viewed as adding a "quality" dimension to the consideration of the quantity of people.

Before a detailed discussion of the effects of educational attainment on demographic and other outcomes, it is useful to examine the more conventional standard demographic dimensions of age and sex. One counter-argument to giving educational attainment such prominent standing is that age and sex are natural determinants, while education is a purely social construction. But let us look critically at the "naturalness" of these two characteristics. Our thinking about age is dominated by what is traditionally called "fixed chronological age," defined as the time measured in years that has elapsed since birth. However there are many different ways of looking at age and ageing as referring not just to chronological age, but to biological, mental, and social maturity. These different conceptions are not only constructs by scientists, but are deeply embedded in traditional cultures. For example, demographers in Australia had problems constructing life tables for the aboriginal population because in that culture individuals often did not know their chronological age. Age and ageing were seen as a succession through different life cycle phases that varied in length depending on different dimensions of maturity as assessed by the elders. Another example is the frequent occurrence of "age heaping" in the censuses of developing countries in which people are not able to state their precise age. The "heaping" often approximates age to a round number such as 40 or 50 .

Even in modern Western societies it has become fashionable to point to the many shortcomings of the deeply engrained concept of chronological age as a basic determinant of behavior and social organization. This is reflected in recent anti-agediscrimination legislation that makes it illegal to use chronological age as a decisive criterion for many relevant decisions. Even the universities are turning from chronological age as a criterion for support of "young” scientists to duration-defined criteria such as "time since doctorate". The European courts recently decided that as a matter of principle "seniority based earnings systems" are illegitimate because they represent a form of age discrimination. As to public perception of the issue, probably the most relevant change has been the rethinking of the meaning of age with respect to health status and remaining life expectancy. It has become a frequent saying that "60 is the new 50" or "70 is the new 60," implying that people aged 70 today are in many important dimensions equivalent to those aged 60 some time ago. There is scientific evidence supporting this popular perception.

Demographers are slowly picking up these new ideas about redefining age and ageing. But the idea of adjustment is not new; Ryder (1975) and Shryock and Siegel (1993) had made suggestions in this direction and Fuchs (1984) even made the more general point that ages should be adjusted for changing life expectancy routinely in the same way that financial variables are adjusted for inflation. Lutz, Sanderson and Scherbov (2008) have applied these ideas to recalculating adjusted ageing indicators on 
a global level. Sanderson and Scherbov (2010) have published such adjustments based on trends in age-specific disability rates rather than just mortality. They write:

"Disability-free life expectancies, which describe how many years of life are spent in good health, have also been increasing, often as fast as unconditional life expectancies, because of decreases in age-specific disability rates. For example, in the United States, the proportion disabled in the age group 65 to74 declined from $14.2 \%$ in 1982 to $8.9 \%$ in 2004-5. Thus, fixed chronological ages do not work well in evaluating the effect of age structure changes on health care costs, because most of those costs occur in the last few years of life, which happen at ever later ages as life expectancies increase.” (p. 1287).

Although measures of age-specific functioning based on disability may be biased by for instance social and cultural influences - which could potentially bias comparisons across cohorts and nations, also research based on objective measures of performance, including assessments of cognitive functioning based on standardized tests, show that there are in fact improvements across subsequent cohorts among those aged 50 and above (Skirbekk et al. 2013; Gerstorf et al. 2011). Such gains are likely to have taken place earlier in some countries than in others, partly as educational expansions have taken place at different periods which thereby could contribute to differences in in age-specific cognitive functioning across countries. This could be a reason why many countries that are chronologically young, such as India, have been found to be cognitively "older" than demographically older regions such as the Nordic countries (Skirbekk et al. 2012).

Scherbov et al. (2013) present the results of our new projections in terms of indicators based on different definitions of "age". Here it suffices to say that the measurement and interpretation of age is neither natural nor uncontested and clearly contains important elements of social construction. As discussed in the Epilogue of the volume, this also has far reaching consequences for future social policies, including pension systems.

As to the second standard differentiation in demographic analysis and forecasting, gender or sex, the ubiquitous distinction between men and women has also been losing some of its self-evident nature and is increasingly understood to be at least in part a social construction. Even the purely biological distinction between the two sexes is not as clear as it was assumed to be. An increasingly vocal trans-gender lobby is complaining about being forced to make choices that are perceived as violations of the group's human rights. In Australia the courts recently ruled that in all official documents persons must not be forced to state their sex as either male or female, but can also choose "indeterminate, intersex, or unspecified". Similarly, Nepal's Supreme Court has ordered the government to alter passports so that transgendered persons no longer have to describe themselves as male or female (Channel News Asia, 14 June 2013). With respect to the more socially determined gender roles and norms, there is little doubt that the traditional male/female distinction is increasingly blurred, while female behavioral patterns and life styles have become less distinguishable from those of males. This is also reflected in the changing sex differentials in mortality and migration. In many countries female smoking behavior now mirrors that of men (and in some cases increases while male smoking declines). Indeed, the male-female difference in life expectancy is in some cases less pronounced than the educational differences. This is 
discussed in detail in Fuchs and Goujon (2013). A similar change in traditional sex differentials can also be observed for migration, where increasing female labor force participation is leading to more female labor migration.

In sum, in $21^{\text {st }}$ century demography traditional age and gender distinctions are losing their previously unquestioned "natural" and absolute deterministic power, while at the same time educational attainment is increasingly recognized as a key determinant of people's behavior and life course outcomes, with significant educational differentials from cradle to grave (Lutz 2010). Hence, we no longer face a situation in which there are presumably natural factors (age and sex) that are on an ontologically different level from other factors that are assumed to be merely socially constructed (such as educational attainment). We now understand that all three factors have elements of social construction, as well as real physiological differences. The fact that there also is a physiological impact of education on the synaptic structure of our brains with consequences for our perception, memory, personality, and behavior is not well-known among social scientists and will be discussed in the following section.

\subsection{Functional Causality in the Context of Intervention Sciences}

An important prerequisite for suggesting the addition of educational attainment as a third demographic dimension is the assumption that the effects of education on demographic behavior and outcomes are not spurious associations, but real and causal in nature. A comprehensive review of the ongoing and controversial social science debate about what constitutes causality and under which conditions it can be assumed or rejected is beyond our scope. Instead, we present our working definition of causality that is employed in this book. This definition includes a brief discussion of the new epistemological concept of "Intervention Sciences" and the associated concept of "Functional Causality". In presenting these concepts, we specify three criteria that need to be met in order to consider the effect of educational attainment on demographic outcomes as causal, and discuss the extent to which we see these criteria as being met.

An important stating point is the view that the assessment of causality in the social sciences is context specific. In this book the context is the field of demographic analysis and, more specifically, the field of population forecasting. As discussed above, it is conventionally taken for granted in this field that a person's age and sex have direct and stable causal relationships to many different demographic outcomes (births, deaths, migrations etc.) and therefore changing age and sex structures of populations can meaningfully be used to forecast future trends in demographic outcomes. This is the basic paradigm that underlies the cohort-component projection model of population projections which, as discussed in Lutz and Butz (2013), is the virtually unchallenged and universally used approach to population forecasting. In this specific context we propose that educational attainment should henceforth be routinely added to age and sex using the well-established methods of multi-dimensional cohort-component projection.

Another relevant epistemological consideration in this context is a distinction between "identity sciences" and "intervention sciences," as recently suggested by Lutz (2012). Under this view of the social sciences and humanities there is a basic distinction that depends on the goal of the analysis: Identity sciences address the questions of "who are we" and "where are we coming from," both at the micro-level of individuals and at the macro-level of societies. These questions, which can include both qualitative and 
quantitative components, relate to a more general view of how the world functions and do not refer to any specific goal of forecasting or directly influencing the course of events. Intervention sciences, on the other hand, try to understand how the most important forces of change function in order to predict the future evolution of the system. The predictions can be based on no intervention, or on alternative interventions and their likely consequences. Since human systems are not strictly deterministic, all such assessments need to consider uncertainty, either probabilistically or in the form of alternative scenarios as is done in this volume. In the research effort presented here, we clearly take an intervention sciences approach. This implies an understanding of causality. We are satisfied with functional causality, which is based on plausible and not contradicted functional relationships between forces that can be assumed to hold for the societies and for the periods to which they are applied. This is distinguished from strong causality, which is harder to assess in the social sciences and typically can only be tested through planned randomized or natural experiments. This approach has been inspired by the work on interventions and functional causal models of Pearl (2000).

The specific distinction between functional and strong causality in the context of intervention sciences is first introduced here and will be elaborated elsewhere by the first author of this paper. We note only that strong causality as it is often assumed in the natural sciences is almost impossible to establish in the social sciences. This is partly due to the difficulty of conducting planned experiments with human subjects and societies without violating human rights, and also to the fact that unlike in the natural sciences, it cannot be assumed that all individuals and all societies around the world behave and react in the same ways even if the external conditions are the same. In a comprehensive review on causation in demography Ní Bhrolcháin and Dyson (2007) specify ten criteria that are supportive of causal inference regarding demographic change. The three criteria discussed below have been inspired by their work.

The following review of the literature about the effects of education on health/mortality and fertility cites many findings from so-called natural experiments. When such experiments support causality for one specific population group in one country at one time, it is far from clear that this demonstrated relationship also holds in very different cultures at different stages of social and economic development. Such observations can strengthen the case for assuming more generally valid causality but they cannot prove it for all societies and all times. Hence, in order to use such relationships as a basis for projections for all countries in the world we do not attempt to demonstrate strong causality, but focus on establishing functional causality through assessing the following three criteria:

(a) There must be strong empirically observed associations between the two factors studied and those associations should hold across different societies and for different sub-groups of the population, and for different points in time (considering the appropriate lag structures). The case for a causal relationship is significantly strengthened if this association is observed both at the individual level (across people and households) and the aggregate level (across societies), in particular when it can be found in longitudinal cohort studies. As stated above, the presence of the effect in (natural) experiments further strengthens the case for general functional causality, although this does not automatically imply validity across all societies. In this paper and the forthcoming book (Lutz et al. 2013) we present empirical evidence regarding such empirical associations. 
(b) There must be a plausible narrative about the mechanisms through which one force influences the other. This explanation must tend to the sequence and timing of events according to the general principle that the cause must always lie before the consequence. In the social sciences it is important to consider that the expectation of a coming event, not just the event itself, qualifies as a cause of behavior. We discuss below what is known about how education influences the brain and behavior. The more specific mechanisms through which changes in level of education affect fertility and health/mortality will be the topic of the following sections.

(c) Other obvious competing explanations of the observed associations should be explicitly and systematically studied and ruled out as playing major dominant roles. Below we examine the two principal alternative explanations of the observed associations between educational attainment and various outcomes, which are selfselection and reverse causality.

Self-selection would imply in the case of the education-health/mortality link, for example, that the observed strong association is explained by the genetic endowment of some individuals with both better health and higher intelligence, resulting in both better educational attainment and greater longevity. We review below several natural experiments that test this hypothesis at the individual level. First, there is an aggregate level argument that provides strong evidence against self-selection as the cause of the strong association between education and health. Assuming for the purpose of argument a time-invariant distribution of genetic predispositions in any population, than an expansion of educational attainment to broader segments of the population should lead to a reduction in the health/mortality advantage, if self-section were a dominant factor. Moving from an elitist educational structure in which only a very select group of people could get educated to a more inclusive one, people from the bottom part of the distribution would move to the educated category, thus reducing the degree of selectivity. However, empirical evidence from around the world clearly shows that in virtually all populations an expansion of education (in some cases even a very rapid expansion such as in South Korea) has resulted in significant increases in overall health and a continuation of the relative health advantage of the better educated people.

In a comprehensive global assessment of the relationship between education and adult mortality KC and Lentzner (2010) also show that at a given time (thus implying a similar global frontier knowledge in medical technology) on all continents (i.e. for very different levels of socio-economic development) for all adult ages and for men and women alike, the less educated segments of the population have significantly higher mortality and morbidity (measured in terms of ADLs) than those who are better educated. This evidence is inconsistent with the proposition that self-selection explains the general patterns of association between educational attainment and related outcomes. The other alternative explanation, reverse causality, is largely irrelevant with respect to mortality because most adult deaths happen after completion of education and by definition mortality removes people from the study population. If health is considered instead of mortality the pattern gets more complex because children with health problems may be less likely to attend school and more likely to experience premature death. While this may be the case in some developing countries the evidence from highly developed countries where even children with serious health problems receive the best possible education also shows strong education gradients in mortality. 
The reverse causality argument could be more relevant for fertility. For example, girls dropping out of school because of pregnancy, or being discouraged from further education because of the presence of young children, might well have lower educational attainment. While this undoubtedly happens, the relative importance of this factor can be tested empirically. In developing countries, for example, the causality can only go from basic education to fertility because basic education of girls is generally completed before reproductive age. Accordingly, the empirical evidence presented in this volume and other major surveys (e.g. Bongaarts 2010) shows significant and robust negative associations between education received before reproductive age and subsequent levels of fertility. Hence, reverse causation is unlikely to play a dominant role in explaining the strong empirical associations between education, on the one hand, and fertility and mortality, on the other.

Before discussing more deeply the empirical evidence concerning the causal effects of education on health/mortality and fertility-related behavior, we address the beginning of the causal chain, the basic biological mechanisms through which learning and in particular systematic learning through formal education changes the physiology of the brain. Modern brain research leaves no doubt that every learning experience and especially repeated experiences change our brains physiologically by building new synapses that store the information about our experiences, and thus produce learning. Eric Kandel, who received the 2000 Nobel Prize in Medicine and Physiology for his path-breaking work on memory, remarked: "Let us repeat this point once more and now it is stored in your brains, and when you walk out through this door you are physiologically a different person from when you walked into the room" (Austrian Science Day, New York, Sept. 10, 2011). In his book In Search of Memory (2007), Kandel provides a systematic account of what is known about the storage of information in the brain and how learning experiences change brain structures for the rest of a person's life. He notes that even twins with identical genes have different brains because of different life experiences (p. 218). Because such physiological changes are difficult to show anatomically in humans, Kandel studied them primarily in Aplysia (a sea slug with particularly large neurons), for which he could demonstrate that learning experiences (such as repeated stimuli of the tail) led to the growth of new synaptic connections, anatomical change that involves the synthesis of new protein (p. 256). In humans specialized learning and repeated activity changes the size of certain parts of the brains and reduces the energy used for certain activities once routine has been gained (Elbert et al. 1995; Jenkins et al. 1990). While neuroscience is still far from a full understanding of the process of learning, neurological studies have confirmed that neurological structures, brain volumes, and cortical thickness can be affected by additional education (Mårtensson et al. 2012; Richards \& Hatch 2011).

If it is accepted that education changes our brains and how we process and store information, which according to Kandel (2007) is also the basis for our sense of personality, then it follows that education also changes other cognitive dimensions, including our perception of the environment, our view of the future, our degree of rationality, and ultimately our behavior resulting from these mental processes. Indeed, empirical studies show that better educated individuals tend to have a longer investment horizon, be more risk averse and have fewer mental health problems (Meijer et al. 2009; van der Pol 2011; Murphy \& O’Leary 2010). Psychosocial factors, such as a sense of 
control, anxiety, depression, social isolation, and stress are also linked to school attainment level (Matthews et al. 2010).

Regarding general cognitive functioning, several studies that assess the effects of exogenous changes in compulsory education show that cognitive functioning is related to the length of schooling and give strong evidence that this effect is causal. Brinch and Galloway (2011) investigated the lengthening of Norwegian compulsory schooling and found that it caused a growth in general intelligence by more than a fifth of a standard deviation for male conscripts. Glymour (2008) examined extensions to compulsory schooling laws in the US and found that these reforms improved cognitive function among seniors. Schneeweis et al (Forthcoming) investigated the long-term effects of extensions to education on mental ability among seniors in Europe, finding that these education reforms significantly improved functioning at several cognitive ability levels, including immediate recall.

\subsection{Effects of Education on Health and Mortality}

Moving from the effect of education on general cognitive functioning to the effects on health-related behavior and mortality, we first note two recent comprehensive assessments and then a larger number of specific studies. Baker et al (2011) offers a meta-analysis of the education effect on adult mortality with data from 29 studies with a total of 69 reported effects covering a sample of more than 20 million adults. All studies consistently showed that less education was associated with higher likelihood of death. The pooled education effect showed that people with low education (lower secondary or less) had a 46 percent higher probability of dying than people with high school or higher education. This study stressed that these effects are likely causal, pointing in particular to the neurological and cognitive impact of schooling as a mechanism. The above mentioned survey by KC and Lentzner (2010) illustrates the effect of education on health and disability, using data primarily from the World Health Survey (WHS). They show that consistently and across all ages and continents, for both men and women separately, higher education is associated with lower rates of disability. The association across four education categories is in all cases monotonic, with the change from no education to primary usually showing the strongest impact on health. They also provide an extensive review of the possible mechanisms by which education influences health and mortality (including behavioral risk factors, psychosocial factors, and multi-factor models), which strongly suggests that these are indeed causal mechanisms at work.

In terms of more specific studies, between 1949 and 1962, Sweden implemented a one-year increase in compulsory schooling where each year children in a number of municipalities were exposed to the reform and others were kept as controls $(\mathrm{N}=$ $1,247,867$, of whom 92,351 died). A study based on the resulting data found that this one-year extension reduced both-sex mortality risk from overall cancer, lung cancer, and accidents. In addition, women reduced their risk of cardiovascular disease mortality and men reduced their death risk from external causes (Lager \& Torssander 2012). Overall, there was significantly lower mortality in the group that took the compulsory schooling, and this group had lower mortality from causes known to be related to education, such as smoking. Similarly, Lleras-Muney (2005) found that variation in compulsory schooling in the US is causally associated with adult mortality, such that an 
additional year of education lowers the probability of dying in the next 10 years by three to six percentage points.

However, effects are not uniform across all studies. In France, Albouy and Lequien (2009) studied the effects of the increase in minimum school leaving age from 13 to 14 for cohorts born after 1923, and later for an additional two years for cohorts born after 1953. Based on Regression Discontinuity (RD) and two-stage estimation approaches, the authors found that these reforms did not result in significant declines in mortality. Changes in compulsory schooling in England were identified as reducing morbidity levels in one study (Silles 2009); however, Clark and Royer (2010) failed to find effects of the English compulsory schooling extensions of 1947-53 on mortality. In Sweden, an extension of schooling from 7 or 8 years, depending on municipality, to 9 years nationally, affecting cohorts born between 1946 and 1957, reduced male mortality up to age 50for those assigned to the reform, but the gains were erased by increased mortality later on (Meghir et al. 2012). An analysis of several European school reforms found that the beneficial educational effects tended to be concentrated among men, with few effects for women (Gathmann et al. 2012). While these studies of changes in the length of compulsory education provide good examples of natural experiments that avoid some of the concerns about self-selection and generally support (and never contradict) the case for assuming a causal relationship of varying strength from length of schooling to health, they only refer to small changes in length of schooling in industrialized countries with high levels of public health services.

A recent study on differential trends in life expectancy in the United States finds actually widening differences by level of education (Olshansky et al. 2012). Drawing from a range of data sources they find that in 2008 US adult men and women with fewer than twelve years of education had life expectancies not much better than that of all adults in the 1950s and 1960s. They find that since then the education differtials have widened and their analysis suggests that in addition to its indirect effects through giving access to better jobs and higher incomes education also has a direct effect on both health and duration of life. As a consequence they suggest policies of educational enhancements for all segments of the population.

Now we turn to the broader global pattern.

There is ample empirical evidence of a pervasive pattern in which mortality levels tend to decrease with the level of education over time, both at the individual and aggregate levels, and in both poorer settings with high income inequality and richer, more egalitarian nations (Govingdasamy \& Ramesh 1997; KC \& Lentzner 2010; Murphy et al. 2006). Education has been found in many countries to correlate with longer lives, better health, and improved physical and mental functioning (Dikshit et al. 2012; Mackenbach et al. 1999; Shkolnikov et al. 2012; Sachan et al. 2012). Although most of the research into education effects on morbidity or mortality has focused on western countries, negative relationships of education with morbidity have also been identified in South Korea, Japan, and other countries (Khang et al. 2004; Kondo 2012). Educational differences in health are often larger in poorer nations; e.g., child mortality differentials by maternal education are relatively high in sub-Saharan Africa and Asia (Monden \& Smits 2012). An extensive multi-level study covering all recent Demographic and Health Surveys (DHS) showed that maternal education is the single most important determinant of child survival at all levels and that its effects on child 
survival are clearly stronger than those of household wealth or income (Fuchs et al. 2010). There are also large differences in health by human capital for seniors in developing countries, as evidenced in India, where self-rated health is significantly positively related to education (Alam \& Karan 2011).

Larger datasets that go beyond the analysis of specific surveys that have limited sample size can improve the knowledge base and increase the ability to identify causal effects. Administrative registration data with high or full national coverage spanning longer time periods allow large-scale population-based research to be carried out with a decreased risk of sample bias. Such datasets are increasingly available for research purposes in a number of nations, including the Nordic countries. Such data sources have been used to investigate the effect of education on lifetime outcomes, including analyzing the effects of schooling on morbidity and lifespans. Some of the largest available studies, including those with full population coverage and a relatively broad set of control variables, suggest a strong positive association of education with longevity (Strand et al. 2010; Remes et al. 2010; Brønnum-Hansen et al. 2004).

Another important source of information is panel surveys based on repeated interviews of a sample of individuals and containing in-depth questions and tests. These data sets facilitate a significantly better understanding of causal mechanisms by allowing for control of additional individual characteristics beyond what is usually found in register data. However, such surveys often lack the size of administrative national registers and their coverage can be potentially biased. For instance, ageing surveys such as SHARE exclude the institutionalized population in the base sample (Börsch-Supan et al. 2008), which could create a sample bias and limit the general validity and reliability of estimates of the effects of education on health. On the other hand, such surveys can follow changes in health and function over time in more detail than administrative data registers. Several analyses of these surveys find that education has a positive effect on health and cognitive functioning, even after controlling for ability levels early in life (Whalley \& Deary 2001; Richards et al. 2004).

Finally, analyses of pairs of monozygotic twins to identify the effects of education represent an important approach as they can control for inherited influences. When comparing twins with the same genetic make-up and shared pre-natal influences, one can isolate and measure the environmental effects of education while the role of nature (and the pre-natal environment) is held constant. There are, however, limitations to twin studies such as relatively small sample size and the possibility that twins could be a selected group, so that the effects may be less representative of the whole population. Still, studies of monozygotic twins represent an important way of identifying the effects of education after controlling for genetic influences. Several twin studies have found a strong positive effect of education on, for instance, mental health (Haworth et al. 2008; Rodgers et al. 2008).

The evidence discussed here of strong positive associations between education and health in different countries, different points in time, combined with the pervasive evidence from several natural experiments, makes it very plausible to assume that there are clear functional causal mechanisms connecting education to better health and lower mortality. These mechanisms can be assumed to remain valid in the future in the context of population projections by level of education. And, as discussed in the previous 
section, there is strong evidence to doubt that this consistent and strong empirical association is dominated by a self-selection effect.

\subsection{Effects of Education on Fertility}

Turning to the effects of education on fertility, the pattern is more complex. Because survival is a universally shared value, people prefer to survive and see their family members survive. Hence, higher empowerment through education can be expected to translate into better survival with a clear unidirectional effect. It is not the same with fertility, where ideal/desired family size is to a large degree culturally determined and where higher empowerment of women through education may lead either to lower fertility (under conditions in which actual fertility is higher than desired) or to higher fertility (where desired exceeds actual fertility). The case is further complicated by the fact that couples have children, and disagreements can arise between the man and woman, whose outcomes are influenced by female education. Female education changes the power relationship tends to be associated with postponement of childbearing during the finite fertile segment of the female life cycle. Finally, for higher levels of education there is the possibility of reverse causation, i.e. young women dropping out of education because of a pregnancy. In spite of this complexity, the negative association is pervasive for almost all societies, except premodern ones and the most advanced egalitarian ones.

Because the effect of education on fertility is expected to vary over the long term course of demographic transition, it is instructive to start with the long-term historic trends in fertility differentials. Skirbekk (2008) provides a comprehensive meta-analysis of available data sets on historical differentials by level of education and/or social status from 1300 to the present. His analysis illustrates that relative wealth (typically of the man) or position in a social hierarchy was positively associated with the level of fertility in the pre-demographic transition era. A plausible explanation for this is that under the prevalence of very high fertility norms - as can be found in virtually all traditional pretransition societies - higher social status facilitates a better achievement of these ideals. Furthermore, higher social status women tended to have better health status and receive more support from nannies so that they could physically have more children.

Over time, however, this positive effect of social status on fertility became less pronounced, particularly in the latter half of the 20th century. Indeed, female education has been negatively associated with fertility for as long as education has been measured. Particularly in developing countries that are still in the midst of the fertility transition, the negative association is very strong. In Ethiopia, for example, the DHS data show that women without formal education have more than six children on average whereas women with secondary or higher education have only two children.

Increasing education levels are widely considered key cause of fertility decline during the demographic transition (Basu 2002; Martin \& Juarez 1995; Cleland 2002). Education tends to be associated with a delay in the onset of childbearing and lower fertility outcomes. A close examination of the mechanisms at work suggests that these effects are causal and not solely driven by selection into schooling (e.g., those who would have fewer children in any case attain a higher education). Education has been found to depress fertility preferences, raise female autonomy, increase contraceptive practice, raise the opportunity costs of having children, and postpone the timing of childbearing (Jejeebhoy 1995; Kravdal 2002; Gustafsson 2001). 
In a comprehensive review of the evidence for sub-Saharan Africa, Bongaarts (2010) examines the factors that contribute to this pervasive negative association. Looking at data from DHS surveys in 30 countries, he demonstrates that education levels are positively associated with demand for and use of contraception and negatively associated with fertility and desired family size. He also finds that as education rises, fertility is lower at a given level of contraceptive use, contraceptive use is higher at a given level of demand, and demand is higher at a given level of desired family size. He concludes that the most plausible explanations for these shifting relationships are that better educated women marry later and less often, use contraception more effectively, have more knowledge about and access to contraception, have greater autonomy in reproductive decision-making, and are more motivated to implement demand because of the higher opportunity costs of unintended childbearing. Given this convincing narrative it is indicative that Bongaarts chose to give this paper the title "The causes of educational differences in fertility ...”.

Regarding the possibility of reverse causation in high fertility countries, the most likely case is young women stopping their education because of an early pregnancy resulting in a birth. While pattern has been found, particularly in some African contexts, it is only a minor factor and cannot explain the overall pattern. This can be demonstrated by looking at educational differentials up to junior secondary education, i.e. before reproductive age, where the differentials are most pervasive. Alternatively, one can restrict the sample to women who only started childbearing after age 18 or 22; within this sub-sample the association appears to be equally strong. Some of this empirical analysis is discussed in Basten et al. (2013).

In many developing countries age at marriage is another important intermediate variable in the relationship. There is strong evidence that early basic education is associated with later age at marriage. In Vietnam, for instance, longer education has been found to increase marital choice. Using household data, where war disruptions and spatial indicators of schooling supply act as statistical instruments, it is estimated that a year of additional schooling reduces the probability of an arranged marriage by about 14 percentage points (Smith et al. 2009).

As mentioned above, in low fertility industrialized countries the differentials tend to be smaller but the association with female education is still clearly negative in most cases. This also seems related to the timing of the onset of childbearing. Education could also have self-reinforcing effects on fertility timing, where increasing levels of education create a race where one needs to have more and more schooling in order to be "on par" or better than others of the same sex-cohort group (Lutz et al. 2006; Skirbekk \& KC 2012). This can imply that education results in fertility being increasingly postponed for each successive generation, since education levels gradually increase and more years of schooling are needed to reach a given percentile in the educational distribution. Several natural experiments suggest causal effects from educational extensions to a delay in the age of fertility in early adulthood. This phenomenon has been identified in very different contexts where school reforms have taken place, for instance in Norway and Turkey (Monstad et al. 2008; Kýrdar et al. 2011).

One study (Skirbekk et al. 2004) uses Swedish school age laws that cause variation in the school leaving exit age based on birth month (those born in January exit school at an age 11 months older than those born in December). As all children born in 
a calendar year enter and exit school at the same time, and their month of birth is random, the resulting variation in the school leaving age is not likely to be related to other individual characteristics. Skirbekk et al. found that this variation in school leaving age had strong effects on parental age at the first childbirth. The difference of 11 months in the age at leaving school between women who were born in the two consecutive months, December and January, implied a delay in the age at first birth of 4.9 months. This may be explained by the fact that there exists a relatively rigid sequencing of demographic events in early adulthood, and the age at graduation from school emerges as an important factor in determining the timing of family formation. These findings are also relevant for studying the level of fertility because postponement of childbearing not only depresses aggregate period fertility measures through the tempo effect, but tends to reduce cohort fertility through apparent tempo-quantum interactions (Kohler et al. 2006).

The global empirical evidence concerning the association between female education and fertility is comprehensively reviewed and discussed in Basten et al. (2013) and Fuchs and Goujon (2013). Here it suffices to say that the assumptions used in our projections assume a gradual narrowing of educational fertility differentials with the progress in demographic transitions. But the assumptions also consider country- and culture-specific differences, taking account in particular of certain countries where differentials are already very low.

In conclusion, we emphasize the convincing narrative of a causal effect of female education on the advance of the fertility transition in terms of the famous three preconditions of a lasting fertility decline as identified by Ansley Coale (1973). First, fertility must be regarded as being within the realm of conscious choice. It is evident that the transition from a more fatalistic attitude to a more rational planning attitude is closely associated with the transition from illiteracy to a more educated status. Second, there must be objective advantages to lower fertility. This is where the higher opportunity costs for more educated women come into play. Moreover, educated women tend to have higher aspirations for the education of their children and understand that they be better able to afford this if they have fewer children. This corresponds to Gary Becker's (1981) point of a quantity-quality transition. Third, Coale stresses that acceptable means of fertility regulation must be readily available. Here again, there is ample evidence from all societies that more educated women find better and easier access to family planning services and contraception than less educated women and are better empowered to overcome possible objections from their husbands and extended families. Surveys show that in every society, from least developed Mali and Niger to the socially most developed Nordic countries, less educated women have a higher rate of unwanted pregnancies than more highly educated women.

All of the literature and evidence presented in this section suggest that all three of the specified criteria are being met to assume functional causality from higher education to better health and thus lower mortality for both men and women and from higher female education to lower fertility, at least over the course of the demographic transition. This causal presumption, in turn, underlies the assumptions and scenarios that are the foundation for the population projections presented in this book. We now turn to the knowledge base of these assumptions and to the way they can be derived through expert argumentation. 


\section{How are the Assumptions for Population Projections Defined?}

"Can knowledge improve forecasts?" was the title of a famous paper by Nathan Keyfitz (1981), in which he expresses the view that demographic trends are easier to forecast than many social and economic trends which are often seen as drivers of fertility and mortality. But how should the demographic trends themselves be forecast? What should be the basis for assumptions about future fertility, mortality, and migration trends? Ahlburg and Lutz (1999), in the introduction to a special issue of PDR on the topic "Frontiers of Population Forecasting" (Lutz et al. 1999), interpret this view of Keyfitz (after discussions with Nathan Keyfitz at IIASA) by suggesting that demographic trends should not be entirely derived from other forecasts (as in the World 3 Model of the "Limits to Growth" by Meadows et al. 1972), or based on blind extrapolation or replication of past trends. Instead, they suggest summarizing the scientific community's knowledge base concerning future demographic trends through a structured process of expert solicitation. This view was also inspired by the influential work of Armstrong and colleagues on forecasting outside the realm of demography (Collopy \& Armstrong 1992), which demonstrated that structured judgment outperforms either judgment alone or a statistical model alone (Ahlburg \& Lutz 1999). This insight guides the approach chosen in this study.

In parallel to the scientific discussion, the practice in statistical offices has been moving in this direction of using structured expert judgment for defining the assumptions. Virtually all national statistical agencies in the world, as well as intergovernmental agencies such as the United Nations (until recently) and Eurostat, have been producing regular population projections by age and sex, following the cohortcomponent projection method with assumptions on future fertility, mortality and migration based on expert judgement

It is worth noting here that the United Nations Population Division (UNPD) recently (since the 2010 assessment) decided to go into a very different direction which bases assumptions largely on a statistical model using only past national level time series within the context of a particular structure and disregards whatever substantive knowledge there exists in the international scientific community about the country- and region-specific factors influencing future fertility, mortality and migration trends. A detailed comparison of the approach chosen in this volume with the new UN approach is currently in progress and will be published elsewhere. At this point is suffices to say that the two approaches follow quite different forecasting philosophies. While the new UN approach essentially assumes that the best we can assume is that the future will see a replication of past trends interpreted within the framework of their model - which essentially makes the entire demographic research community redundant when it comes to producing projections - we chose to follow the alternative path of making the substantive arguments upon which our forecasts rest explicit. We did this by improving the structured procedures for soliciting country-specific expert knowledge and significantly enlarging the number of experts involved in the process to over 500 . And as described in detail in Lutz et al. (2013) the substantive expert assessment of alternative arguments relevant for the future trends will be blended with formal statistical models much in the spirit recommended by Collopy and Armstrong (1992). 
In this section we first review the current practice of statistical agencies in the European region and note a survey that indicated near consensus on the need for improving the procedures by which expert knowledge is assessed as the basis for making assumptions. The main results of the survey was that the offices charged with making population projections would welcome more structured interactions with the demographic research community. We then discuss the proposal for a systematic argument-based approach to making demographic assumptions that was developed under the European Commission's "MicMac" project ("Bridging the micro-macro gap in population forecasting", www.nidi.nl/micmac) and has been operationalized for the projections presented in this volume.

In 2005, all national statistical offices (NSOs) of the European Union countries were asked to provide information on their procedures for producing their most recent population projections. Each office received from Eurostat a IIASA-designed questionnaire, which 21 out of 25 national statistical offices returned. The results of this survey were documented in Prommer and Wilson (2006) and Lutz (2009). The most common procedure was to create scenarios that cover a "plausible" range of future fertility, mortality, and migration. The involvement of external experts and meetings was generally considered very important, but all national statistical offices suggested that the methods used to make assumptions could use further improvements.

As the most desirable procedure, one NSO explicitly stated: "We base our assumption on facts and reasoning. We try to present as many facts as possible and we also try to specify where we are uncertain and show how and why we have decided in a certain way. We also try to describe the reasoning behind the assumptions thoroughly in the publication about the population projection.”

The NSOs were also asked about the best directions for such improvements. The following three improvement options were most frequently endorsed: (a) "have a more systematic review of all the substantive arguments behind the assumptions" (b) "have some structured interactions with the European demographic research community about the state of the art in our knowledge about future demographic trends", and (c) "involve more experts".

In a nutshell, this extensive and informative enquiry among EU national statistical offices shows that all national offices consider the current practice for defining the assumptions for population projections as sub-optimal and needing further improvement. The results further indicate the direction in which to move: Have a more systematic review of the substantive arguments behind the assumptions in the form of a structured interaction with the demographic research community, which also facilitates the involvement of more experts.

This important view from the practitioners of population projections, together with the theoretical insights discussed above provided the basis for the new expertargument based approach that was developed at IIASA and has now been broadly applied to defining the assumptions for the set of global population projections presented in this volume. This process involved more than 500 population experts from around the world who answered the online questionnaire or participated in one of the five Meta-expert meetings. Before describing the design and conduct of this exercise, it useful to step back and discuss some of the general problems associated with any kind 
of expert solicitation regarding future trends, and with the general reluctance of academics to make statements about the future.

\subsection{The Meta-Science of Expert Knowledge}

Given the public prominence and substantive importance of likely future demographic trends in virtually all countries of the world, we find it surprising how little systematic attention the scientific community has given to the evaluation of arguments underlying the assumptions of future fertility, mortality and migration trends. While the abovedescribed survey shows that national statistical offices place hope in input from the demographic research community, this topic has largely been confined to the statistical agencies. Since these offices cannot avoid making choices about assumptions in order to fulfill their mandate of producing population projections, they cannot escape this challenging task as easily as academics seem to be able to. Our approach attempts to translate the vast body of relevant research in the demographic community and other related research communities into specific sets of science-based assumptions for projections. This follows earlier work by Lutz, Saariluoma, Sanderson and Scherbov (2000), that explicitly discusses some of the shortcomings of expert based procedures. Such procedures typically follow the tradition of Delphi methods that have been developed and extensively documented elsewhere (Linstone \& Turoff 2002).

The main problem with expert opinions is that they tend to be opinionated; this can result in undesirable biases and distortions that do not necessarily reflect the state of knowledge. There is abundant evidence that experts tend to hold strong beliefs about the future that are at the level of emotions and intuitions (Lutz 2009). Hence, the approach proposed here goes beyond opinion-based Delphi to embody a more objective sciencebased procedure. Of course, whenever one relies on the views of people, the result cannot be fully objective, but one can move toward objectivity by making the process inter-subjective and applying the standard scientific tools of peer review and critical evaluation. In order to make progress there must be something on the table to be evaluated and analytically reviewed. Hence, our argument-based approach puts specific arguments on the table that are directly relevant for the future course of the demographic force under consideration and which can be critically assessed.

In designing this new argument-based approach, we collaborated with an experimental psychologist working in the field of cognitive science, who is an expert on experts. We learned that one important contribution that meta-science can make to any scientific approach is to investigate problems in the way arguments are built in particular scientific fields. Such an investigation can help applied scientists find a more analytical way of thinking in their own fields. It is important to understand that all scientific argumentation ends somewhere, and from that point on the operation of intuitive assumptions begins. Infinite chains of arguments are impossible. Being aware of this, one should reflect on when to end the chain of argumentation. This point might be right next to the object of observation, in which case there is no argumentative foundation at all. It can also be too far away from the object, in which case the arguments considered and the objects are linked only tentatively. The choice of this cutoff point needs to be based on expert judgment. But this is judgment at the meta-level rather than at the level of the object itself. Such judgment must be based on some sense of plausibility or intuition, as it is typically called in cognitive science and foundational 
analysis. Hence, intuitions in the foundations of scientific ways of thinking are unavoidable. We cannot get around them; we have to learn to live with them, and the best way to do so is to be cognizant of the known traps and fallacies and to be entirely transparent about the choices made.

\subsection{The Systematic Inquiry of Expert Arguments Chosen for this Study}

Based on these considerations and principles, a team at IIASA and the Vienna Institute of Demography (VID) designed an on-line questionnaire with separate segments for fertility, mortality, and migration. The questionnaire was developed gradually, first only with respect to mortality when it was tested with a group of 17 mortality experts in the context of the above mentioned MicMac project (Lutz 2009). It was then further operationalized and programmed in Excel by the National Office of Statistics in the United Kingdom, which used it for systematically collecting expert-based assessments on fertility, mortality, and migration for $\mathrm{t}$ population projections. A team at IIASA further developed the questionnaire for its broader use for all countries. For each of the three segments the arguments were grouped according to selected major forces that were defined to be as independent from each other as possible.

For fertility and mortality six such major forces were identified, and for international migration five. They are:

Major forces on which future fertility $(\mathrm{F})$ will depend:

F1. Changing cultural and social forces in fertility ideals, norms and desires

F2. Changing patterns of partnerships and gender differences

F3. Changing roles of government policies (child care facilities, housing, etc.)

F4. The changing environment in terms of employment and the economy

F5. Changing bio-medical conditions (sperm quality and counts, female

fecundability, new methods for assisted conception, etc.)

F6. Changes in educational attainment

Major forces on which the future of life expectancy (L) will depend:

L1. Progress in biomedical technology

L2. Changes in the effectiveness of health care systems

L3. Changes in health-related behavior

L4. Possible new infectious diseases and resurgence of old diseases

L5. Environmental change, disasters and wars

L6. Changes in population composition and differential trends in population subgroups

Major forces influencing international migration (M):

M1. Trends in economic development as a driver of international migration

M2. Climate change and conflict as possible drivers of international migration

M3. Demographic factors as a possible driver of international migration

M4. Changes in the costs of migration (in the broader sense)

M5. Trends in migration regimes and policies

For each of these 17 major forces up to 10 specific arguments were listed, with responding experts invited to add additional self-defined arguments. These specific arguments are listed and discussed in Basten et al. (2013), Fuchs and Goujon (2013), Caselli et al. (2013), Garbero and Pamuk (2013), and Sander et al. (2013) dealing with 
fertility, mortality, and migration. ${ }^{2}$ For each of the arguments the experts were asked to judge the degree of correctness based on the scientific evidence. They were given five predefined choices about the validity of the argument ("very likely to be right", "more right than wrong”, "do not know/ambivalent”, "more wrong than right”, "very likely to be wrong"). As can be seen from Figure 1, which provides a screen shot of one of the argument assessment pages, these answers were translated into a numerical factor (in parentheses below) ranging from 0.0 for "very likely to be wrong to" to 1.0 for "very likely to be right”.

Whether the argument is right is not all that matters; the relevance of the argument for influencing the future course of the force under consideration is also important. Some arguments may likely be true, but completely irrelevant for the question under consideration. Hence, experts were asked a second question concerning the likely impact of each argument on the demographic component (see Figure 1), which says, "Regardless of your answer above, if the above argument were completely true, what effect would this have on the future of ...”. Again the user could choose among five answers ranging from "strongly decreasing" (assigned a factor of -1.0) to "strongly increasing" (assigned a factor of +1.0). If the respondent believes that the factor has no effect on the demographic outcome considered, then this answer is assigned to zero.

In a final assessment, the two factors stated for any given argument are multiplied, with the total argument impact score automatically shown, as in the scale at the bottom of Figure 1. This multiplicative assessment of the degree of the statement's correctness and of its impact if correct can thus range from strong negative impact, given by -1.0 (when the statement is considered correct and to have a strong negative impact), to a strong positive impact given by +1.0 (when the statement is considered incorrect and to have a strong positive impact). If the statement is either considered to be wrong or right but having no impact the total impact score (resulting from the multiplication of the two scores) is zero. These scores have then been further processed as described in the Lutz et al. (2013).

In mid-2011 all members of international population associations (IUSSP, PAA, EAPS, APA and all other regional population associations) were invited to participate in the online survey. More than 550 responses were submitted. The lead authors of this volume, most of whom are affiliated with the Wittgenstein Centre, systematically analysed the responses and led a series of five Meta-Expert workshops to review and focus them. These specialized workshops consisted of groups of 8-12 leading experts in the respective fields. Between October 2011 and February 2012 the meetings were held on five continents: Migration (Boulder, Colorado.), Low Fertility (Vienna), High Fertility (Kathmandu), Low Mortality (San Jose, Costa Rica) and High Mortality (Cape Town). Based on these meetings, we defined alternative education-specific fertility, mortality and migration assumptions for all countries, as is described in detail in Lutz et al. (2013).

\footnotetext{
2 The full questionnaire can be found at http://webarchive.iiasa.ac.at/Research/POP/ExpertSurveySandbox/
} 


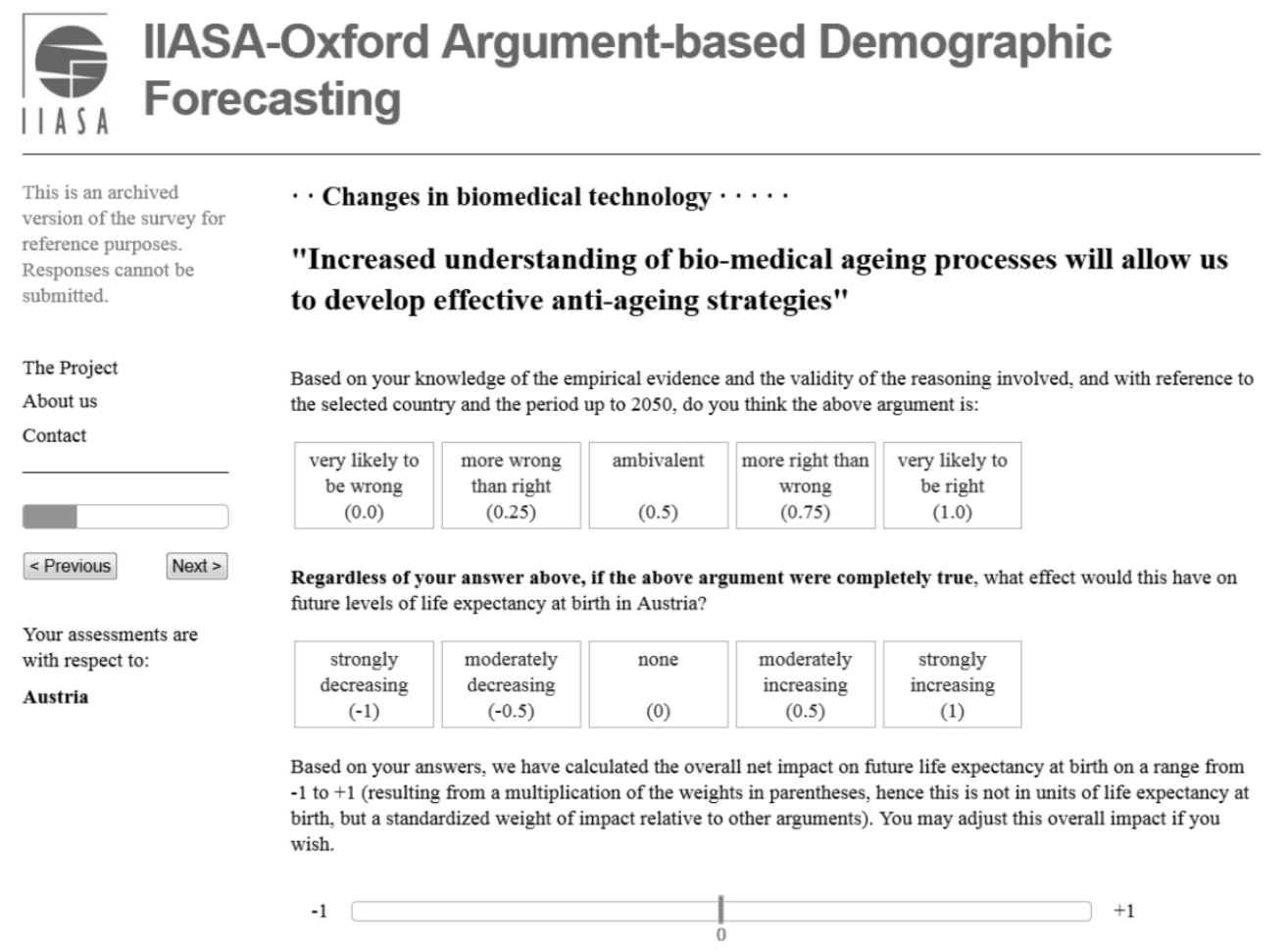

Figure 1: Screen shot from a sample page of the online questionnaire listing one argument on future life expectancy under the force "Changes in biomedical technology".

\section{References}

Ahlburg, D.A. and W. Lutz. 1999. Introduction: The Need to Rethink Approaches to Population Forecasts. Pages 1-41 in W. Lutz, J. W. Vaupel, and D. A. Ahlburg, eds., Frontiers of Population Forecastin. A Supplement to Vol. 24, 1998, Population and Development Review. New York: The Population Council.

Alam, M. and A. Karan. 2011. Elderly Health in India: Dimension, Differentials and Determinants. United Nations Population Fund.

Albouy, V. and L. Lequien. 2009. Does compulsory education lower mortality? Journal of Health Economics 28(1): 155-168.

Baker, D.P. et al. 2011. The education effect on population health: a reassessment. Population and Development Review 37(2): 307-332.

Basten, S., T. Sobotka, and K. Zeman. 2013. Future Fertility in Low Fertility Countries. in W. Lutz, W. P. Butz, and K. C. Samir, eds., World Population and Human Capital in the 21st Century. Oxford University Press, forthcoming.

Basu, A.M. 2002. Why does education lead to lower fertility? A critical review of some of the possibilities. World Development 30: 1779-1790.

Becker, G.S. 1981. A Treatise on the Family. Cambridge, Massachusetts: Harvard University Press.

Bongaarts, J. 2010. The causes of educational differences in fertility in Sub-Saharan Africa. Vienna Yearbook of Population Research 8: 31-50.

Börsch-Supan, A. et al. 2008. First Results from the Survey of Health, Ageing and Retirement in Europe (2004-2007): Starting the Longitudinal Dimension. Mannheim: Mannheim Research Institute for the Economics of Aging (MEA). 
Brinch, C.N. and T.A. Galloway. 2011. Schooling in adolescence raises IQ scores. Proceedings of the National Academy of Sciences 109(2): 425-430.

Brønnum-Hansen, H. et al. 2004. Social gradient in life expectancy and health expectancy in Denmark. Sozial- und Präventivmedizin 49(1): 36-41.

Caselli, G. et al. 2013. Future Mortality in Low Mortality Countries. in W. Lutz, W. P. Butz, and K. C. Samir, eds., World Population and Human Capital in the 21st Century. Oxford University Press, forthcoming.

Clark, D. and H. Royer. 2010. The Effect of Education on Adult Health and Mortality: Evidence from Britain. National Bureau of Economic Research.

Cleland, J. 2002. Education and Future Fertility Trends with Special Reference to MidTransitional Countries. New York: United Nations.

Coale, A.J. 1973. The Demographic Transition Reconsidered. Pages 53-72 in International Population Conference, Committee on South-North Migration. Liege: International Union for the Scientific Study of Population.

Collopy, F. and J.S. Armstrong. 1992. Rule-based forecasting: development and validation of an expert systems approach to combining time series extrapolations. Management Science 38(10): 1394-1414.

Dikshit, R. et al. 2012. Cancer mortality in India: a nationally representative survey. The Lancet 379(9828): 1807-1816.

Elbert, T. et al. 1995. Increased cortical representation of the fingers of the left hand in string players. Science 270(5234): 305-307.

Fuchs, R. and A. Goujon. 2013. Future Fertility in High Fertility Countries. in W. Lutz, W. P. Butz, and K. C. Samir, eds., World Population and Human Capital in the 21st Century. Oxford University Press, forthcoming.

Fuchs, R., E. Pamuk, and W. Lutz. 2010. Education or wealth: Which matters more for reducing child mortality in developing countries? Vienna Yearbook of Population Research 8: 175-199.

Garbero, A. and E. Pamuk. 2013. Future Mortality in High Mortality Countries. in W. Lutz, W. P. Butz, and K. C. Samir, eds., World Population and Human Capital in the 21st Century. Oxford University Press, forthcoming.

Gathmann, C., H. Jürges, and S. Reinhold. 2012. Compulsory Schooling Reforms, Education and Mortality in Twentieth Century Europe. Rochester, NY: Social Science Research Network.

Gerstorf, D. et al. 2011. Cohort differences in cognitive aging and terminal decline in the Seattle Longitudinal Study. Developmental Psychology 47(4): 1026-1041.

Glymour, M.M. et al. 2008. Does childhood schooling affect old age memory or mental status? Using state schooling laws as natural experiments. Journal of Epidemiology and Community Health 62(6): 532-537.

Govingdasamy, P. and B.M. Ramesh. 1997. Maternal Education and the Utilization of Maternal and Child Health Services in India. Mumbai, India, Calverton, MD: International Institute for Population Sciences and Macro International Inc.

Gustafsson, S. 2001. Optimal age at motherhood. Theoretical and empirical considerations on postponement of maternity in Europe. Journal of Population Economics 14(2): 225-247.

Haworth, C., P. Daleb, and R. Plomin. 2008. A twin study into the genetic and environmental influences on academic performance in science in nine year old boys and girls. International Journal of Science Education 30(8): 1003-1025. 
Jejeebhoy, S. 1995. Women's Education, Autonomy and Reproductive Behaviour: Experience from Developing Countries. Oxford: Clarendon Press.

Jenkins, W.M. et al. 1990. Functional reorganization of primary somatosensory cortex in adult owl monkeys after behaviorally controlled tactile stimulation. Journal of Neurophysiology 63(1): 82-104.

Kandel, E.R. 2007. In Search of Memory: The Emergence of a New Science of Mind. New York: W.W. Norton \& Co.

KC, S. and H. Lentzner. 2010. The effect of education on adult mortality and disability: A global perspective. Vienna Yearbook of Population Research 8: 201-235.

Keyfitz, N. 1981. The limits of population forecasting. Population and Development Review 7(4): 579-593.

Khang, Y.H. et al. 2004. Trends in socioeconomic health inequalities in Korea: use of mortality and morbidity measures. Journal of Epidemiology and Community Health 58(4): 308-314.

Kohler, H.-P., F.C. Billari, and J.A. Ortega. 2006. Low Fertility in Europe: Causes, Implications and Policy Options. Pages 48-109 in F. R. Harris, ed., The Baby Bust: Who Will Do the Work? Who Will Pay the Taxes? Lanham, MD: Rowman \& Littlefield Publishers.

Kondo, N. 2012. Socioeconomic disparities and health: impacts and pathways. Journal of Epidemiology 22(1): 2-6.

Kravdal, Ø. 2002. Education and fertility in sub-Saharan Africa: individual and community effects. Demography 39(2): 233-250.

Kýrdar, M.G., M. Dayýoglu Tayfur, and Ý. Koç. 2011. The Effect of Compulsory Schooling Laws on Teenage Marriage and Births in Turkey. Bonn: Institute for the Study of Labor (IZA).

Lager, A.C.J. and J. Torssander. 2012. Causal effect of education on mortality in a quasi-experiment on 1.2 million Swedes. Proceedings of the National Academy of Sciences 109(22): 8461-8466.

Linstone, H.A. and M. Turoff eds. 2002. The Delphi Method: Techniques and Applications. Digital reproduction of the original 1975 version. Newark, NJ: New Jersey Institute of Technology.

Lleras-Muney, A. 2005. The relationship between education and adult mortality in the United States. The Review of Economic Studies 72(1): 189-221.

Lutz, W. 2010. Education will be at the heart of 21st century demography. Vienna Yearbook of Population Research 8: 9-16.

Lutz, W. 2012. Identity Sciences und Intervention Sciences: Was die Geistes- und Sozialwissenschaften leisten können. Thema 11: 3.

Lutz, W. et al. 2000. New Developments in the Methodology of Expert- and ArgumentBased Probabilistic Population Forecasting. Laxenburg, Austria: International Institute for Applied Systems Analysis (IIASA).

Lutz, W. 2009. Toward a Systematic, Argument-Based Approach to Defining Assumptions for Population Projections. Laxenburg, Austria: International Institute for Applied Systems Analysis (IIASA).

Lutz, W. and W.P. Butz. 2013. Introduction. in Wolfgan Lutz, W. P. Butz, and K. C. Samir, eds., World Population and Human Capital in the 21st Century. Oxford University Press, forthcoming.

Lutz, W., W.P. Butz, and S. KC eds. 2013. World Population and Human Capital in the 21st Century. Oxford University Press, forthcoming. 
Lutz, W., A. Goujon, and G. Doblhammer-Reiter. 1998. Demographic dimensions in forecasting: Adding education to age and sex. Population and Development Review 24(Supplementary Issue: Frontiers of Population Forecasting): 42-58.

Lutz, W. and S. KC. 2010. Dimensions of global population projections: what do we know about future population trends and structures? Philosophical Transactions of the Royal Society B: Biological Sciences 365(1554): 2779-2791.

Lutz, W. and S. KC. 2011. Global human capital: integrating education and population. Science 333(6042): 587-592.

Lutz, W., W. Sanderson, and S. Scherbov. 2008. The coming acceleration of global population ageing. Nature 451(7179): 716-719.

Lutz, W., V. Skirbekk, and M.R. Testa. 2006. The low-fertility trap hypothesis: Forces that may lead to further postponement and fewer births in Europe. Vienna Yearbook of Population Research 2006: 167-192.

Lutz, W., J.W. Vaupel, and D.A. Ahlburg eds. 1999. Frontiers of Population Forecasting. A Supplement to Vol. 24, 1998, Population and Development Review. New York: The Population Council.

Mackenbach, J.P. et al. 1999. Socioeconomic inequalities in mortality among women and among men: an international study. American Journal of Public Health 89(12): 1800-1806.

Mårtensson, J. et al. 2012. Growth of language-related brain areas after foreign language learning. NeuroImage 63(1): 240-244.

Martin, T.C. and F. Juarez. 1995. The impact of women's education on fertility in Latin America: searching for explanations. International Family Planning Perspectives 21(2): 52-80.

Matthews, K.A., L.C. Gallo, and S.E. Taylor. 2010. Are psychosocial factors mediators of socioeconomic status and health connections? Annals of the New York Academy of Sciences 1186(1): 146-173.

Meadows, D.H. et al. 1972. The Limits to Growth: A Report for the Club of Rome's Project on the Predicament of Mankind. New York, NY: Universe Books.

Meghir, C., M. Palme, and E. Simeonova. 2012. Education, Health and Mortality: Evidence from a Social Experiment. National Bureau of Economic Research.

Meijer, W.A. et al. 2009. Interaction effects of education and health status on cognitive change: A 6-year follow-up of the Maastricht Aging Study. Aging \& Mental Health 13(4): 521-529.

Monden, C.W. and J. Smits. 2012. Maternal education is associated with reduced female disadvantages in under-five mortality in sub-Saharan Africa and southern Asia. International Journal of Epidemiology.

Monstad, K., C. Propper, and K.G. Salvanes. 2008. Education and fertility: evidence from a natural experiment. Scandinavian Journal of Economics 110(4): 827852.

Murphy, M. et al. 2006. The widening gap in mortality by educational level in the Russian Federation, 1980-2001. American Journal of Public Health 96(7): 1293-1299.

Murphy, M. and E. O’Leary. 2010. Depression, cognitive reserve and memory performance in older adults. International Journal of Geriatric Psychiatry 25(7): 665-671.

Ní Bhrolcháin, M. and T. Dyson. 2007. On causation in demography: issues and illustrations. Population and Development Review 33(1): 1-36. 
Olshansky, S.J. et al. 2012. Differences in life expectancy due to race and educational differences are widening, and many may not catch up. Health Affairs 31(8): 1803-1813.

Pearl, J. 2000. Causality: Models, Reasoning, and Inference. Cambridge, U.K.; New York: Cambridge University Press.

Van der Pol, M. 2011. Health, education and time preference. Health Economics 20(8): 917-929.

Prommer, I. and C. Wilson. 2006. Analytical Summary of the Current Practices of Definition of Assumption Making in Population Projections. Laxenburg, Austria: International Institute for Applied Systems Analysis (IIASA).

Remes, H., P. Martikainen, and T. Valkonen. 2010. Mortality inequalities by parental education among children and young adults in Finland 1990-2004. Journal of Epidemiology and Community Health 64(2): 130-135.

Richards, M. et al. 2004. Cognitive ability in childhood and cognitive decline in midlife: Longitudinal birth cohort study. British Medical Journal 328(7439): 552554.

Richards, M. and S.L. Hatch. 2011. Good news about the ageing brain. British Medical Journal 343(1): d6288-d6288.

Rodgers, J.L. et al. 2008. Education and cognitive ability as direct, mediating, or spurious influences on female age at first birth: behavior genetic models fit to Danish twin data. American Journal of Sociology 114 Suppl: 202-232.

Ryder, N.B. 1975. Notes on stationary populations. Population Index 41(1): 3-28.

Sachan, B. et al. 2012. Social determinants and its influence on the prevalence of morbidity among adolescent girls. North American Journal of Medical Sciences 4(10): 474-478.

Sander, N., G. Abel, and F. Riosmena. 2013. The Future of International Migration. in W. Lutz, W. P. Butz, and K. C. Samir, eds., World Population and Human Capital in the 21st Century. Oxford University Press, forthcoming.

Sanderson, W.C. and S. Scherbov. 2010. Remeasuring aging. Science 329(5997): 12871288.

Scherbov, S. et al. 2013. Remeasuring 21st Century Population Ageing. in Wolfgan Lutz, W. P. Butz, and K. C. Samir, eds., World Population and Human Capital in the 21st Century. Oxford University Press, forthcoming.

Schneeweis, N., V. Skirbekk, and R. Winter-Ebmer. Forthcoming. Does education improve cognitive performance four decades after finishing school? Demography.

Shkolnikov, V.M. et al. 2012. Increasing absolute mortality disparities by education in Finland, Norway and Sweden, 1971-2000. Journal of Epidemiology and Community Health 66(4): 372-378.

Shryock, H.S. and J.S. Siegel. 1993. The Methods and Materials of Demography. 8th ed. Washington, D.C.: US Government Printing Office.

Silles, M.A. 2009. The causal effect of education on health: Evidence from the United Kingdom. Economics of Education Review 28(1): 122-128.

Skirbekk, V. 2008. Fertility trends by social status. Demographic Research 18(5): 145180.

Skirbekk, V. et al. 2013. The Flynn effect and population aging. Intelligence 41(3): 169-177. 
Skirbekk, V. and S. KC. 2012. Fertility-reducing dynamics of women's social status and educational attainment. Asian Population Studies 8(3): 251-264.

Skirbekk, V., H.-P. Kohler, and A. Prskawetz. 2004. Birth month, school graduation, and the timing of births and marriages. Demography 41(3): 547-568.

Skirbekk, V., E. Loichinger, and D. Weber. 2012. Variation in cognitive functioning as a refined approach to comparing aging across countries. Proceedings of the National Academy of Sciences 109(3): 770-774.

Smith, S.C., M.S. Emran, and F. Maret. 2009. Education and Freedom of Choice: Evidence from Arranged Marriages in Vietnam. The George Washington University, Institute for International Economic Policy.

Strand, B.H. et al. 2010. Educational inequalities in mortality over four decades in Norway: prospective study of middle aged men and women followed for cause specific mortality, 1960-2000. British Medical Journal 340(feb23 2): c654c654.

Whalley, L.J. and I.J. Deary. 2001. Longitudinal cohort study of childhood IQ and survival up to age 76. British Medical Journal 322(7290): 819. 